references in the headlines of Nature News stories and other similar articles.

A quick scan of a few issues yields: “...over a pork barrel”; "Oceanography: Churn, churn, churn”; "...science in premier league”; "State of the donation"; "Astrophysics: The answer is blowing in the wind"; "Scot on the rocks"; and "The silence of the robins". As a native English speaker I may understand and appreciate these, but many others wouldn't Jeff Craig

Epigenetics Research Laboratory, The Murdoch Childrens Research Institute, Royal Children's Hospital, Flemington Road, Parkville, Victoria 3052, Australia

\section{Puns: wimp or macho, not a particle of offence is meant}

SIR - Beyond the excellence of the scientific reporting, I particularly enjoy the entertaining use of language and the enlightened levity of Nature. Consequently, I am somewhat concerned by the complaint of R. M. Ned and L. N. Steele ('Slang's not so slick when you remember its origins' Nature 447,775 ; 2007) regarding the use of the verb 'pimp', because of its "immoral origins".

Should I take offence because the use of the terms 'wimp' and 'macho' to denote putative particles might perpetuate negative stereotyping of my gender?

The freedom and, especially, the humour of scientific reporting may be hindered by misguided attempts to avoid offending moralists.

\section{Milan Hopkins}

9479 Main Street, PO Box 638,

Upper Lake, California 95485, USA

\section{Regions unite to challenge inequalities in Brazil}

SIR - The "unequal struggle" of mediumsized university physics departments in Scotland "against larger and moreentrenched rivals" is highlighted by your Editorial 'All for one...' (Nature 447, 1031; 2007). The less developed countries of the world face an even greater problem. How can science help the economic improvement of these countries, taking into account not only "basic challenges in trying to compete globally", but also regional difficulties particularly very limited facilities and insufficient human resources?

As an illustration of the regional problem, take the Human Development Index, which measures quality of life: a score above 0.5 is medium and above 0.8 is high. The south of Brazil scores about 0.84 - not far behind some European countries - whereas the northeast of Brazil is around 0.67.

Along the same lines as the Scottish Universities Physics Alliance described in your Editorial, the Brazilian government and universities created the Northeast Network on Biotechnology, or Renorbio (www. renorbio.org.br) in 2003. Last year a graduate programme in biotechnology was added, consisting of a pool of 29 universities from 10 different Brazilian states.

This initiative is new in the following five ways. It aims to produce $100 \mathrm{PhD}$ graduates a year, which should speed regional development. Many universities that were not strong enough previously to offer a $\mathrm{PhD}$ programme now can, and will also gain research funds. Researchers who join the programme qualify for $\mathrm{PhD}$ students. The universities are becoming more competitive both locally and internationally. They are now expected to produce more patents and publications, creating stronger departments and leading to an increase in the number of knowledge-based enterprises in the region. Luiz A. B. Castro ${ }^{\star}$, Allan Kardec Barros' ${ }^{\star}$ R\&D Policies and Programmes,

Ministry of Science and Technology,

Esplanada dos Ministérios, Bloco E, Brasília, DF, 70067-900, Brazil

$\dagger$ Department of Electrical Engineering, Federal University of Maranhao, Av. dos Portugueses, s/n, Sao Luis, MA, 65080-040, Brazil

\section{Summing up The Simpsons}

SIR — In your amusing News Feature interview with Harvard mathematics graduate $\mathrm{Al}$ Jean, head writer of The Simpsons ('Mmm... Pi' Nature 448, 404; 2007), Jean mentions, as an example of a staggeringly obscure mathematical reference, a number in the thousands that is the sum of four squares. However, as

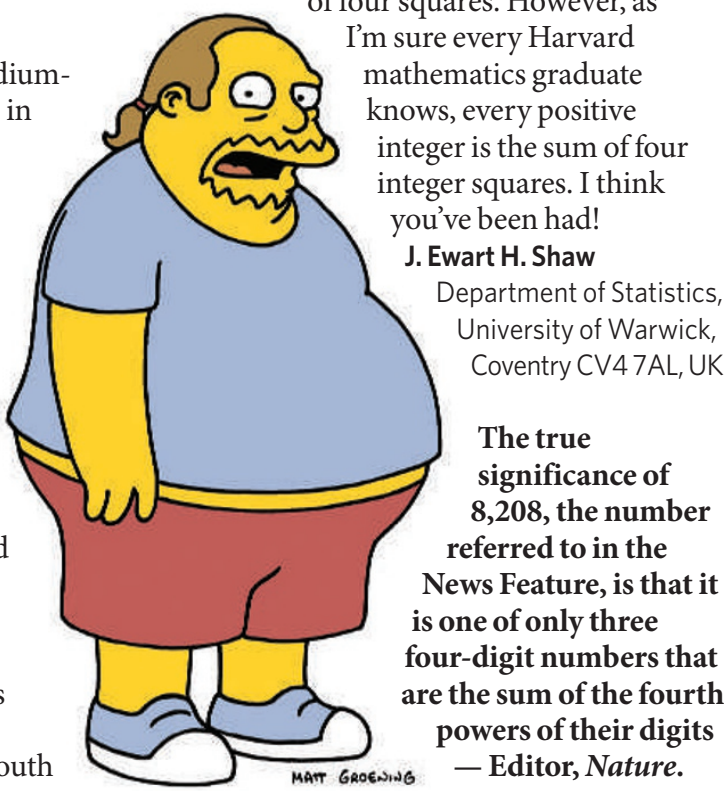

\section{Drop 'higher' and 'lower' to raise descriptive standards}

SIR - For most of the past 2,500 years, the dominant view in the West was that life was graded from better to worse, higher to lower, in a Chain of Being. This could be the product of some creative deity or - as in the eighteenth- and nineteenth-century theories proposed by Denis Diderot, Jean Baptiste de Lamarck and Robert Chambers - a consequence of matter somehow organizing itself through a goal-directed, progressive evolutionary process. Humans invariably occupied the top link.

The scientific literature persists in providing a home for the terminology of the Chain. During the past year, for instance, the Nature.com search facility identifies more than 300 references to 'higher' or 'lower' eukaryotes or organisms.

This usage is misleading, because evolution is not a progressive process. Selection may, in the short term, lead to increases in fitness. But there is no reason to assume that species adapted to the environments they occupy today are better adapted than their precursors were to their environments, and if evolution does not ensure this it hardly qualifies as progressive. Of course, because the first life forms were very simple, it is not surprising that evolution has resulted in increases in specialization or complexity in many lineages. But there is no sense in which such changes can make one taxon higher than another.

An argument in favour of preserving the terminology of the Chain is that it is useful. Yet there is considerable disagreement over the referents of 'higher' and 'lower'. The status of plants, for example, as higher or lower organisms is very fluid. Yeast is typically a 'lower' organism when compared with animals but can be a 'higher' one when compared with bacteria. Perhaps more disturbingly, and in a usage reminiscent of natural theology, non-human mammals can be relegated to the group of lower organisms when they are compared with humans.

A descriptive terminology hardly qualifies as useful if users disagree over what it describes. Moreover, it is rarely the case that using a consistent and scientifically robust terminology is more difficult than using the inconsistent and misleading terminology of the Chain. Distinguishing between plants and animals, for example, or between flowering and non-flowering plants, or between vertebrates and invertebrates, or between humans and other primates/ mammals/animals without resorting to the descriptors 'higher' and 'lower' is easy it's just been done.

Michael Mogie

Centre for Mathematical Biology, Department of Biology and Biochemistry, University of Bath, Bath BA2 7AY, UK 